\title{
Corrigendum: Spatial task context makes short-latency reaches prone to induced Roelofs illusion
}

\author{
Bahareh Taghizadeh ${ }^{1,2}$ and Alexander Gail ${ }^{1,2,3 *}$ \\ ' Sensorimotor Group, Cognitive Neuroscience Lab, German Primate Center, Goettingen, Germany \\ ${ }^{2}$ Faculty of Biology and Psychology, Georg-August-Universität, Göttingen, Germany \\ ${ }^{3}$ Bernstein Center for Computational Neuroscience, Göttingen, Germany \\ *Correspondence: agail@gwdg.de \\ Edited by: \\ J. Douglas Crawford, York University, Canada \\ Reviewed by: \\ Lore Thaler, Durham University, UK \\ Thomas Schenk, Universitätsklinikum Erlangen, Germany
}

Keywords: reach movement, induced Roelofs effect, Illusion, reference frame, allocentric, object-centered

\section{A corrigendum on}

Spatial task context makes short-latency reaches prone to induced Roelofs illusion by Taghizadeh B., and Gail A. (2014). Front. Hum. Neurosci. 8:673. doi: 10.3389/fnhum. 2014.00673

The authors regret errors in the reported subject numbers and values for the illusion size in the data for individual subjects. This affects experiments Ia, Ib, II, and IIa. This mistake does not affect any of the conclusions of the paper since the reported mean values and standard errors were all correct. Correct values for the illusion size in the $N$ individual subjects for each experiment are as follows:
E Ia $(N=11)$ :

$4.13^{\circ} 4.69^{\circ} 0.30^{\circ} 2.08^{\circ} 4.70^{\circ} 1.11^{\circ} 4.15^{\circ}$

$1.93^{\circ} 4.37^{\circ} 1.27^{\circ} 4.16^{\circ}$

$\mathrm{E} \operatorname{Ib}(N=9)$ :

$\begin{array}{lllll}0.17^{\circ}-0.03^{\circ} & 0.13^{\circ} & 0.42^{\circ} & 0.25^{\circ} & 0.09^{\circ}\end{array}$

$-0.04^{\circ}-0.14^{\circ} 0.06^{\circ}$

E II $(N=10)$ :

$3.83^{\circ} 3.16^{\circ} 1.91^{\circ} 4.76^{\circ} 4.59^{\circ} 4.33^{\circ} 4.45^{\circ}$

$4.71^{\circ} 5.07^{\circ} 0.26^{\circ}$

E IIa $(N=10)$ :

$4.12^{\circ} 3.33^{\circ} 0.43^{\circ} 4.69^{\circ} 4.26^{\circ} 4.91^{\circ} 4.33^{\circ}$

$4.36^{\circ} 3.36^{\circ} 0.55^{\circ}$

Conflict of Interest Statement: The authors declare that the research was conducted in the absence of any commercial or financial relationships that could be construed as a potential conflict of interest.

Received: 27 September 2014; accepted: 29 October 2014; published online: 14 November 2014.

Citation: Taghizadeh B and Gail A (2014) Corrigendum: Spatial task context makes short-latency reaches prone to induced Roelofs illusion. Front. Hum. Neurosci. 8:923. doi: 10.3389/fnhum.2014.00923

This article was submitted to the journal Frontiers in Human Neuroscience.

Copyright @ 2014 Taghizadeh and Gail. This is an open-access article distributed under the terms of the Creative Commons Attribution License (CC BY). The use, distribution or reproduction in other forums is permitted, provided the original author(s) or licensor are credited and that the original publication in this journal is cited, in accordance with accepted academic practice. No use, distribution or reproduction is permitted which does not comply with these terms. 